Cleft Lip with Unilateral Detachment of Premaxilla.

If the lip can be repaired without interference with the premaxilla, that bone should not be touched, as in the course of time pressure of the repaired lip will put back the prominent bone into good line. If, however, the prominence is so marked that the lip cannot be repaired over it, or only repaired with considerable tension, then the bone requires replacement. It is, I think, useless to attempt to push the bone back into place unless it is fractured at one end. Various methods of producing the fracture are suggested; probably the following are the best.

Method A.-Make a small incision on the alveolar edge where the interval between the lateral incisor and canine on the attached side of the premaxilla would be expected to lie; there insert a small chisel and fracture the bone sufficiently to allow manual replacement.

Method B.-This method was originated by Mr. Staunton in the Children's Hospital, Dublin, to produce a fracture at the site mentioned and leave the overlying mucous membrane intact. A specially devised forceps is used, one blade of which is broad and specially devised forceps is used, one blade of which is broad and
blunt, while the other has a narrower but blunt edge. The forceps is so made that the blades on full compression do not meet, but sufficient space is left to allow the more elastic soft parts to escape whilst the inelastic bone is fractured.

The usual procedure when the bone has been mobilized sufficiently is to pare the edges of the cleft alveolus on either side and to fix the bone by wiring across the cleft. This method is to be condemned as it is unnecessary and difficult; in perforating the bone for the wire teeth on each side of the cleft are often destroyed or detached, and the wire often cuts through, or a piece of the premaxilla may be detached. It is much better to proceed immediately to do the lip operation, as the repaired lip will then act as an efficient splint.

Cleft Lip with Bilateral Detachment of Premaxilla.

This constitutes the most difficult problem in the surgery of the condition; as the bone is frequently displaced far forwards its reduction and retention in place may be extremely difficult. Of course, if the displacement of the bone is slight it_may be possible to bring the lip over it without interfering otherwise with the bone; this fortunate state of affairs, however, is very unusual, and other methods are generally necessary.

The anterior part of the nasal septum, to which alone the projection is attached, must be divided by making a short incision along the lower edge of the nasal septum right down to the bone, separating the soft tissues from the underlying bone, and dividing the denuded septum for the required extent with a small stout pair of scissors.

In these cases it is practically impossible to avoid retention wire sutures to hold the mobilized bone in place. For this purpose, as the premaxillary segment is so small, I have devised a method in which it is necessary only to pierce that segment once, and only in its central thicker part. The best instrument to use for piercing the bone is a very small sized trocar and cannula, the cannula being without a shoulder so that it can be withdrawn through the bone either outwards or inwards. For ease of insertion and avoidance of undue trauma to the small premaxillary segment, I strongly advise piercing and insertion of the wire through that segment before it has been mobilized by division of the septum. The bone is pierced at its centro by the trocar with cannula attached, and the trocar is withdrawn and the two free ends of a silver wire loop are

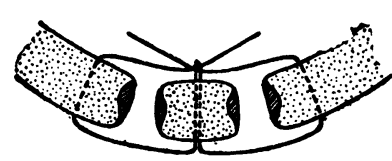

passed from within (from the mouth cavity) outwards, leaving the loop on the in side. Each free end is then drawn in an opposite direction. The superior maxilla Fig. 2.-Horizontal view showing of each side is pierced at method of wiring premaxillary some distance from either element in bilateral detachment. cleft as before, and each free end is returned through the cannula to project on the inside of the mouth. The margins of the cleft are pared, and the suture tightened by drawing the free ends through the loop, pulling them tense, twisting the wire and cutting off any excess (Fig. 2).

The lip may be repaired immediately, or if the ability of the child to stand further operation at the time is questionable, further measures may be delayed for some days.
The repair of the lip defect is carried out as before. The fleshy middle part of the lip attached to the premaxilla is merely freshened by two perpendicular cuts down the sides, and from their lower ends by two angular cuts meeting at the midpoint of the lower border. Mayo's flap method is again employed on the lateral margins of the clefts. Suturing is them carried out, but there is no excess of tissue to be removed. It may be necessary to make lateral cuts into the lip tissue on either side before suturing to secure accurate coaptation of the lateral with the central fleshy segment, and to give fullness to the lip. As even with the premaxilla replaced it is sometimes difficult to avoid tension, it is useful to remember the suggestion of Goyder ${ }^{4}$ in such cases, to do only the repair of one side of the double cleft at the time, and at a subsequent operation, when the wound has soundly healed, to do the other side.

\section{Post-operative Treatment.}

The silk haemostatic sutures at the angles of the mouth are removed immediately on the completion of the operation. The question of fixation of the cheeks by drawing them towards the middle line so as to avoid strain on the suture line has then to be decided. In the majority of my own cases I merely paint the wound with iodine, leave it without covering of any sort, and use no fixation whatever. But if a child is very fretful, and particularly in cases of bilateral clefts, I adopt one of two methods of fixation. The first, by passing two pieces of adhesive plaster, one from the cheek in front of the ear up over the bridge of the nose and down to a corresponding point on the other cheek, the cheeks meanwhile being drawn inwards, and the other from in front of the ear down to the chin and up to a corresponding point on the other side, ${ }^{5}$ to evert the lip and allow a free airway, as well as to aid in relieving tension. The other method also leaves the wound free; it is the use of the Logan traction brace as depicted in Brophy's textbook.

The trend of modern methods in the treatment of the deformity of cleft lip is to use simple methods for the repair of the lip, and to avoid, when at all possible, interference with associated lesions of the alveolus.

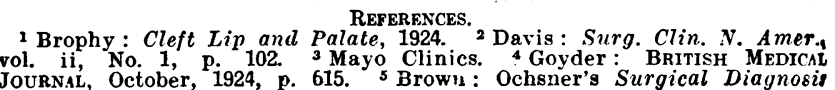
JournaL, October, 1924, p. 615.
and Treatment, vol. $i$, p. 588 .

\section{THE USES OF COELIOSCOPY.}

\section{A. RENDLE SHORT, M.D., B.S., B.Sc., F.R.C.S., SURGEON TO THE BRISTOL ROYAL INFIRMARY.}

As exploratory laparotomy, often referred to as though it were a mere trifle, may be from the patient's point of view a very formidable affair. It involves a general anaesthetic, followed probably by some flatulent discomfort and perhaps anaesthetic vomiting, and two or three weeks in bed, and occasionally some complications with the wound. The expense may be considerable. In cases of carcinoma of the stomach, or malignant pancreas, death may follow so soon after as to raise a suspicion that the operation had something to do with it.

In a certain number of cases, not many perhaps, there is a far less formidable alternative: this is to distend tho abdomen with air, which can be done without serious discomfort under a local anaesthetic through a tiny incision, and to inspect the viscera with a cystoscope. I have been using this method for about a year, and have never seen harm follow. Like every other technical procedure a little trouble must be taken to learn how to get a good view, but it is not more difficult than cystoscopy.

The advantages of coelioscopy over exploratory laparotomy are: (1) it can be done without discomfort under novocain; (2) the incision is so small that it is only neces sary to keep the patient in bed for a day or two; (3) no special instruments are needed; (4) it can be done at the patient's own house; (5) it is available when it would be dangerous to perform laparotomy.

A few examples may be given to illustrate its usefulness. Small malignant nodules have several times been seen on 
the surface of the liver, which in one case clinched an uncertain diagnosis, and in another forbade a drastic operation. In a case in which tuberculous peritonitis was suspected it was easy to see that there were no tubercles on the intestine. The extent of a carcinoma on the surface of the stomach may be discerned. Information may be given as to the nature of swellings of uncertain origin inside the abdomen. I have once or twice seen the appendix presenting itself. Pelvic tumours can be inspected. The method would be available to determine the presence or absence of blood in the abdomen in cases of ruptured ectopic gestation or traumatic rupture of a

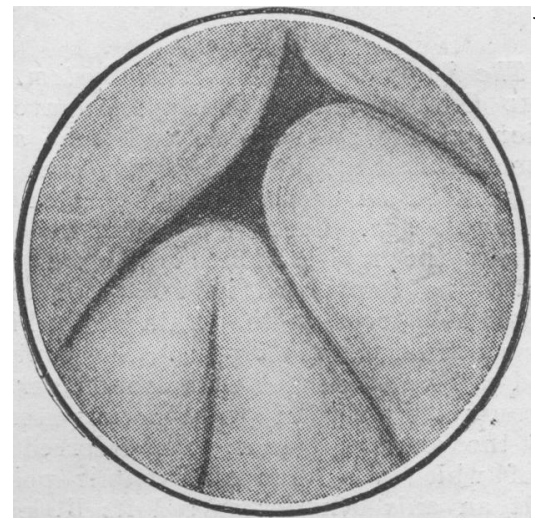

Fro. 1.-Coils of normal small intestine.

viscus. It is easy to see whether the liver is or is not "6 hobnail."

Coelioscopy does not and cannot replace exploratory laparotomy in those cases where the cause may have to be sought for and does not lie on the surface of the abdominal viscera, and these will always be the majority. It is principally valuable for what is definitely seen, and not for what is apparently absent.

The technique is simple. Under novocain anaesthesia, or under ether if preferred, an incision half an inch long is made in the skin and fascia. I usually enter in the middle line just below the umbilicus. Above the umbilicus difficulties with the falciform ligament arise. Layer after layer is picked up with a pair of artery forceps until the peritoneum is opened, the incision being just as large as will admit the cystoscope, but no larger. The cystoscope, sterilized in carbolic solution, is then passed in and the abdomen inflated with air through it. The air is filtered through sterile wool, and an ordinary bellows is all that is necessary. Then the lamp is inserted; the brightest possible light is used. Some risk of fusing the bulb must be run. If the upper abdomen is to be examined the table is tilted to raise the head, and vice versa. I usually commence by finding the edge of the liver on the right side, and then the gall bladder. If the patient is under a local

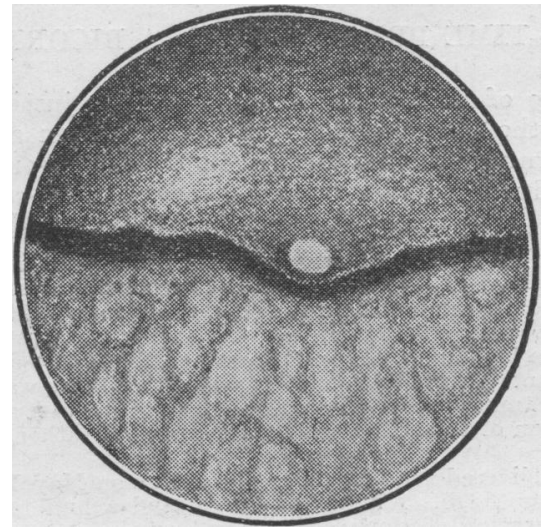

FIG. 2.-The edge of the liver, showing a small nodule of carcinoma on its surface.

anaesthetic the peristaltic movements of the small intestine can be seen. When the examination is finished, the air is let out as completely as possible and a stitch put inunless, of course, the findings are such as to encourage a set operation.

Fig. 1 shows coils of normal small intestine, and Fig. 2 the edge of the liver, with fat lying on the surface of the viscera below it. There is a small nodule of carcinoma on the surface of the liver, secondary to a growth in the rectum; no operation, therefore, could be undertaken. I am indebted to Mr. Sewell for the pictures. They are from two separate cases.

\section{Attemoranda:}

\section{MEDICAL, SURGICAL, OBSTETRICAL.}

\section{PARALDEHYDE POISONING.}

Paraldehyde is not a scheduled poison, but is used extensively as a sedative in mental cases. There are only two cases recorded of death from this drug, one of them being a person suffering from typhoid ferer. A recent case (Liverpool, June, 1925) is interesting and should be put on record.

The person was a man aged 41 , very lightly. built, who had been accustomed for some months to take doses of paraldehyde varying from one to two teaspoonfuls. The source of his supply of the drug up to the present has not been ascertained, and it is probable he had gradually increased the dose. On the last probable he had gradually increased the dose. On 11 p.m. and slept by himself. The next morning at 8 o'clock he was found dead in bed; a glass with half an ounce of paraldehyde, and a 4-ounce bottle containing three-quarters of an ounce of paraldehyde, were by the bedside two other empty 8-ounce bottles were in the room; the washings gave the reactions of paraldehyde. It is estimated that he had taken between $2 \frac{1}{2}$ and 3 ounces. He had had very little food of any kind, and very little stimulant for two or three days before any kind, and very little stimulant for two or three days before from the nose, but no vomiting had taken place.

At the post-mortem examination the innermost exposed portions of the lips were seen to be dry and darker than normal; the mouth smelt of paraldehyde. The mucous membrane of the mouth, epiglottis, larynx, and upper portion of the oesophagus were blanched, and in the lower third of the oesophagus the mucous membrane bore light-coloured coagulated patches.

On opening the body the cavities smelt strongly of paraldehyde. The stomach, normal in size, contained about 5 ounces of turbid fluid, smelling strongly of and giving the reactions for paraldehyde; the mucous membrane was markedly hyperaemic with uniform injection of the small ressels. The hyperaemia was more marked on the back part of the stomach towards the cardiac end. The mucous membrane of the duodenum was more lightly injected, the appearance gradually fading away; the small and large bowels and their contents were normal.

large bowels and their contents were normal. The blood was fluid and dark. The heart showed some small atheromatous patches on the aorta just beyond the aortic valves and at the openings of both coronary arteries; it was otherwise normal. The liver, spleen, kidneys, and brain were quite normal. All the organs seemed to bear the odour of paraldehyde, but it was difficult to eliminate the smell. The bladder contained 14 ounces of urine which smelt very strongly of paraldehyde, and gave the of urine which smelt very
chemical tests for aldehyde.

As the deceased had made his ordinary arrangements and laid out his clothing ready to be put on the next day, the case was taken and returned as one of misadventure. J. E. W. MACFALL, M.D.

Department of Forensic Medicine, University of Liverpool.

\section{RAT-BITE FEVER IN AN INFANT.}

As rat-bite fever, though common in Japan, is rare in England, the following case, which occurred recently in Sunderland, seems worthy of record.

On April 8th an infant was bitten on the right thumb while in bed with its mother; the wound bled profusely. Next day the thumb was somewhat swollen and dark in colour; the back of the hand was also swollen. The child had some bronchitis and appeared ill. During the ensuing week the swelling subsided, the wound healed, and the general symptoms abated. Fifteen days after the bite a scarlatiniform rash appeared about the chest and armpits, together with four swellings, one on each wrist and one just below the sternal end of each clavicle. There was some pyrexia. The child was taken to the Borough Sanatorium, and next day the swellings were incised, thick pus being evacuated. This was placed in broth and some blood smears forwarded to the pathologist, Dr. 